\title{
Idealisasi Nilai Pendidikan Lingkungan dalam Novel Anak Rantau (Kajian Ekokritik)
}

\author{
Nova Agusryana Syarif*, Muhammad Rapi Tang, Usman \\ Program Pascasarjana Universitas Negeri Makassar \\ *Corresponding Author. Email: novasyarif1@gmail.com
}

\begin{abstract}
This study aimed to examined the value of environmental education in the novel Anak Rantau by Ahmad Fuadi. This research used descriptive qualitative method. Data collection method used the documentary method using reading and note-taking technique. Data analysis was carried out through several stages, namely data reduction, data presentation, and drawing conclusions. The result of this study indicated that novel Anak Rantau by Ahmad Fuadi contained the value of environmental education, namely establishing a harmonious relationship between humans and nature by maintaining and caring for nature as well as possible. So that human wisdom and prudence will be created in responding to all natural wealth with everything in it for the sake of human survival in the future.
\end{abstract}

\begin{abstract}
Abstrak: Penelitian ini bertujuan untuk mengkaji nilai pendidikan lingkungan yang terdapat dalam novel Anak Rantau karya Ahmad Fuadi. Metode penelitian yang digunakan yakni jenis penelitian kualitatif yang bersifat deskriptif. Teknik pengumpulan data yang digunakan adalah dokumentasi dengan menggunakan teknik baca dan catat. Analisis data digunakan melalui beberapa tahapan yakni reduksi data, penyajian data, dan penarikan kesimpulan. Hasil penelitian menemukan bahwa dalam novel Anak Rantau karya Ahmad Fuadi memuat nilai pendidikan lingkungan yakni menjalin hubungan harmonis antara manusia dengan alam dengan menjaga dan merawat alam dengan sebaik-baiknya. Sehingga akan tercipta sikap arif dan bijaksanan manusia dalam menyikapi seluruh kekayaan alam dengan segala isinya demi kelangsungan hidup manusia di masa yang akan datang.
\end{abstract}

\section{Article History}

Received: 17-03-2021

Revised: 26-04-2021

Accepted: 03-05-2021

Published: 07-06-2021

\section{Key Words:}

Value, Environmental

Education, Novel,

Ecocriticism.

\section{Sejarah Artikel}

Diterima: 17-03-2021

Direvisi: 26-04-2021

Disetujui: 03-05-2021

Diterbitkan: 07-06-2021

\section{Kata Kunci:}

Nilai,

Pendidikan Lingkungan,

Novel,

Ekokritik.

How to Cite: Syarif, N., Tang, M., \& Usman, U. (2021). Idealisasi Nilai Pendidikan Lingkungan dalam Novel Anak Rantau (Kajian Ekokritik). Jurnal Kependidikan: Jurnal Hasil Penelitian dan Kajian Kepustakaan di Bidang Pendidikan, Pengajaran dan Pembelajaran, 7(2), 306-313. doi:https://doi.org/10.33394/jk.v7i2.3735

dc. https://doi.org/10.33394/jk.v7i2.3735

This is an open-access article under the CC-BY-SA License.

\section{Pendahuluan}

Aspek alam sudah menjadi objek yang diperbincangkan pengarang dalam karya sastra, baik sebagai latar atau sebagai tema. Isu mengenai lingkungan semakin marak terdengar di berbagai media. Hasil analisis Greenpeace Internasional (www.greenpeace.org) menyatakan bahwa terdapat 3.403.000 hektar lahan terbakar tahun 2015 sampai 2018. Perburuan hewan yang dilindungi dan eksploitasi alam dalam bentuk illegal logging merupakan sebuah kondisi yang terus menjadi problematika yang tidah hanya terjadi di perkotaan tetapi juga di pedesaan dengan latar belakang sosiologis masyarakat yang masih memegang teguh adat istiadat dan pengelolaan lingkungan alam secara tradisional (Putri dkk: 2019). Tidak hanya itu, permasalahan lingkungan juga dapat berakibat fatal, seperti terjadinya bencana alam (Andriyani dan Piliang, 2019: Larasati, 2020).

Pendidikan lingkungan perlu digalakkan untuk mencegah terjadinya kerusakan lingkungan yang semakin parah (Afandi dan Juanda, 2020). Kesadaran peduli lingkungan atau kearifan lingkungan diperlukan agar sikap peduli lingkungan dapat terus digalakkan 
demi terciptanya kelestarian ekologi dan kelestarian alam. Dalam dunia akademis terdapat upaya untuk mengatasi kerusakan lingkungan (Budiharto dan Ramadani, 2018; Juanda, 2019b; Sultoni, 2020; Winda dan Bahri, 2020) antara lain dalam pengajaran sastra terkhusus melalui kajian-kajian terhadap karya sastra. Karya sastra memiliki nilai pendidikan lingkungan yang dapat digunakan untuk memberikan pembelajaran kepada para pembaca dan masyarakat serta merupakan cara pengarang karya sastra untuk menyerukan pemeliharaan lingkungan dengan berkomunikasi dengan pembacanya. Beberapa sastrawan yang menggunakan tema alam dalam karya mereka antara lain Ahmad Tohari, Corri Kayun Rampan, Ahmad Fuadi, D. Zawawi Imron, dan masih banyak lagi (Darmawati, 2017).

Studi ekokritik merupakan studi yang mengulas karya sastra dari sudut pandang lingkungan (Glothfelty dan Fromm, 1996; Asyfa dan Putri, 2018). Salah satu bentuk kajian dalam ekokritik yakni pastoral. Pastoral merujuk pada setiap karya sastra yang mendeskripsikan kehidupan pedesaan yang berbeda dengan kota (Gifford, 1999). Studi ekokritik telah dilakukan oleh beberapa ahli di Indonesia yakni Lisnasari dan Sukmawan (2016); Asyfa dan Putri (2018); Juanda (2019); serta Syam dan Aris (2020). Di negara lain pernah dilakukan penelitian oleh Fenn (2015); Anjan dan Sathoskumar (2017); serta Flinn (2018).

Lisnasari dan Sukmawan (2016) mengungkapkan karakteristik pastoral dalam cerita rakyat Tengger menjadi karakteristik narasi puitika teks ekokritik. Bentuk pengetahuan tersebut diperoleh dari pengalaman hidup masyarakat yang kaya akan nilai kearifan lingkungan. Penelitian yang dilakukan oleh Asyfa dan Putri (2018) menemukan bahwa manusia dan alam merupakan satu kesatuan yang saling bergantung dan memengaruhi. Ketika alam menunjukkan gejala yang tidak seimbang dalam kehidupan ekosistemnya, maka manusia yang hidup berdampingan dengannya secara alamiah akan melakukan tindakantindakan penyembangan. Penelitian Juanda (2019a) mengenai ekokritik film avatar sebagaai sarana pendidikan lingkungan siswa dan hasil yang diperoleh yakni film avatar karya James Cameron berisi pendidikan lingkungan kepada siswa yaitu gerakan hijau yang dilakukan suku Navi yang sesuai dengan kearifan ekologis adalah nilai pola laku, pola sikap, dan pola pikir. Syam dan Aris (2020) menemukan adanya hubungan antara manusia dan alam yang menerapkan tiga model yakni model dominasi, model pelindung dan model biosentris.

Selanjutnya Fenn (2015) mengkaji ekokritik di era postmodernisme yang menunjukkan bahwa ekokritik tidak hanya menekankan pada keharmonisan umat manusia dan alam tetapi juga mengenai kerusakan yang disebabkan oleh perubahan yang terjadi di dunia modern yang merupakan tanggung jawab manusia. Anjan dan Sathoskumar (2017) menemukan bahwa penyair India dalam hal ini Ruskin Bond mengungkapkan kesadaran lingkungan melalui karya sastranya. Di sisi lain, Flinn (2018) yang mengkaji ekokritik pastoral terhadap buku kumpulan komik Perancis yang diterbitkan sejak tahun 2010 dan menemukan bahwa adanya ledakan kecil dalam penerbitan buku komik bertema lingkungan yakni pertanian. Berdasarkan penelitian terdahulu dapat diketahui bahwa penelitian-penelitian tersebut belum pernah ada yang meneliti mengenai idealisasi nilai pendidikan lingkungan dalam novel Anak Rantau menggunakan kajian ekokritik. Oleh karena itu dirasa perlu dilakukan penelitian terhadap idealisasi nilai pendidikan lingkungan dalam novel Anak Rantau karya Ahmad Fuadi mengingat bahwa karya sastra dapat digunakan sebagai penghubung untuk mengajarkan nilai-nilai pendidikan lingkungan dalam novel kepada para pembaca dan masyarakat. 


\section{Metode Penelitian}

Penelitian ini menggunakan metode kualitatif yang bersifat deskriptif. Fokus penelitian ini adalah mengkaji idealisasi nilai pendidikan lingkungan dalam novel Anak Rantau karya Ahmad Fuadi menggunakan teori Ekokritik Gifford. Data dalam penelitian ini berupa kata, frasa, klausa, dan kalimat dalam novel Anak Rantau yang memuat idealisasi nilai pendidikan lingkungan menggunakan metode dokumentasi dengan teknik baca dan catat. Teknik analisis data yang digunakan menggunakan teknik analisis Miles dan Huberman (2014) yang terdiri atas tiga tahap yakni reduksi data, penyajian data, dan penarikan kesimpulan.

\section{Hasil Penelitian dan Pembahasan}

Novel Anak Rantau karya Ahmad Fuadi mengajak pembaca untuk kembali merenungi pepatah masyarakat Sumatera khusunya masyarakat Minang. Alam takambang jadi guru. Alam terkembang jadi guru. Pepatah tersebut mengajarkan kita bahwa alam akan memberikan manusia berbagai pelajaran hidup. Kehidupan manusia elang mengajarkan untuk terbang tinggi kemana saja, melintasi batas untuk mencari hidup (Fuadi, 2019:18). Novel Anak Rantau mengisahkan perjalanan Hepi yang pulang ke kampung halaman ayahnya di Minangkabau untuk liburan sekolah. naum kenyataanya kepulangan tersebut dijadikan sebagai alas an ayahnya untuk meninggalkan Hepi Bersama kakek dan neneknya di kampung agar ia bisa belajar menjadi manusia yang bertanggung jawab dengan belajar dari alam Minang yang kental dengan budaya dan adat istiadat yang keras. Ayah Hepi merasa kehidupan Kota Jakarta akan merusak kehidupan Hepi.

Akhir cerita tersebut menggambarkan Hepi yang betah tinggak di kampung halaman ayahnya. Baginya, alam pedesaan, kampung halaman ayahnya adalah tempatnya berguru segala hal. Jakarta sudah semakin jauh. Hatinya sudah lengket dengan kampung (Fuadi, 2019: 352). Nilai pendidikan lingkungan yang terdapat dalam novel Anak Rantau yakni mengenai menjaga hubungan harmonis antara manusia dengan alam dengan menjaga dan memelihara alam dengan baik, kenyamanan bekerja dan tinggal di alam dengan situasi dan kondisi apapun serta dalam kondisi yang serba terbatas.

Hubungan harmonis manusia dengan alam tercermin dalam perilaku manusia menjaga dan merawat alam sehingga terwujud keharmonisan alam dan ekosistem alam tetap terjaga dan seimbang. Untuk mewujudkan keharmonisan tersebut, bentuk nyata yang dapat dilakukan adalah dengan menyayangi dan merawat alam dengan baik. Dalam novel Anak Rantau, tokoh Zen yang merupakan seorang pecinta binatang sehingga dia memelihara dan merawat binatang dengan baik dan mencintai binatang tersebut. Hal tersebut dapat dilihat melalui penggalan kutipan berikut.

(1) Zen yang selalu sayang binatang langsung marah kepada teman-temannya yang menarik-narik badan ular itu. "Kasihan, ini masih anak ular, ekornya luka garagara kalian lempar tadi," katanya sambil mengelus-elus kepala ular tersebut dengan sayang. Lidah merah bercabangnya melet-melet (Fuadi, 2019:90).

(2) Zen yang penyayang binatang terus menatap mata sepasang merpati yang terus berdekut kur-kur di dekat jendela. "Mereka sedih karena sarangnya kena gusur kita," jelas Zen seperti penerjemah resmi. "Macam Nabi Sulaiman saja kau Zen," goda Attar dan disambut cekikikan Hepi. Zen tidak peduli, dan bersungguhsungguh bertukang, membikin kotak kayu berlubang sebagai pengganti rumah merpati yang dia gantungkan di atas atap di luar jendela kaca (Fuadi, 2019:195). 
(3) Zen mengelus-elus kepala setiap kambingnya dan menghela meraka pelan-pelan ke luar kendang. Dan yang membikin Hepi antara gelak dan geli, Zen mencium satu per satu kepala kambing-kambingnya seakan mengucapkan perpisahan. Beberapa mengembik manja dan menggoyangkan ekornya, seperti paham perasaan Zen (Fuadi, 2019: 280).

Berdasarkan kutipan-kutipan tersebut dijelaskan bahwa tokoh Zen menjaga hubungan harmonis dengan binatang dengan menyayangi dan merawat binatang-binatang tersebut baik yang dipeliharanya sendiri seperti kambing pada kutipan (3) maupun yang tidak dipelihara yakni ular yang ekornya terluka pada kutipan (1) serta dia membuat kotak kayu sebagai pengganti sarang merpati yang dia dan kawan-kawannya rebut untuk dijadikan markas persembunyian kelompoknya pada kutipan (2). Sementara itu pada kutipan (4) dan (5) berikut dijelaskan menjaga hubungan harmonis manusia dengan alam tercermin dari perilaku manusia yang mengambil keputusan bersama demi kepentingan alam seperti tergambar dalam kutipan berikut.

(4) Pak Sinayan angkat bicara, "Kita wajib menulis surat kepada pemerintah untuk membatasi jumlah karamba. Agar danau ini tidak jadi kolam beracun raksasa." (Fuadi, 2019: 350)

(5) "Inilah waktunya kita memperbaiki kampung kita sendiri, mambangkik batang tarandam, membangkitkan batang yang sudah terendam lama. Bersama-sama kita tentulah bisa," kata Datuk Malano tidak kalah bersemangat (Fuadi, 2019: 350).

Melalui penggalan novel tersebut dijelaskan bahwa masyarakat kampung durian yang melihat keadaan alam di sekitarnya di mana banyaknya jumlah karamba di danau membuat danau menjadi kolam beracun raksasa. Klausa kolam beracun raksasa menunjukkan bahwa karamba tersebut teah mencemari danau Talago dengan banyaknya pakan ikan yang mengendap di dasar danau menjadikan danau beracun. Oleh karena itu tokoh Pak Sinayan mengajak warga untuk menyurat kepada pemerintah agar membatasi jumlah karamba. Pada kutipan selanjutnya (5) dijelaskan pula bahwa tokoh Datuk Malano yang juga ikut mendukung agar masyarakat kembali bersatu untuk memperbaiki kampung dengan membangkitkan kembali kearifan lingkungan yang selama ini telah tergerus perkembangan zaman.

Nilai pendidikan lingkungan dalam novel Anak Rantau juga menggambarkan kekecewaan tokoh terhadap lingkungan alam yang dulu asri namun lama kelamaan menjadi memprihatinkan. Seperti terdapat dalam penggalan novel berikut.

(6) Sekarang air danau sudah surut, sehingga tepi pantai kini menjauh beberapa meter dari rumah. Kakeknya menuduh air susut gara-gara sungai mengering, akibat adanya penebangan liar di hulu. Selain surut, air sekarang tidak lagi jernih. Sejak ribuan keramba ikan mengapung di danau, air dicemari pakan yang berlebihan dan mengendap di dasar danau. Air yang dulu membiru sekarang berwarna kehijauan dan bau tak sedap beraroma amoniak kerap meruap (Fuadi, 2019: 37-38).

Kutipan (6) tersebut membuka mata kita bahwa kelestarian lingkungan bergantung bagaimana manusia menjaga dan merawat alam tersebut dengan sebaik-baiknya. Akibat adanya penebangan liar di hulu menyebabkan sair sungai mengering sehingga air danau pun turu menjadi surut sehingga tepi pantai semakin menjauh dari rumah. Penebangan hutan dapat menyebabkan kerusakan pada alam dan dapat merugikan manusia serta dapat 
mengakibatkan bencana alam. Oleh karena itu, mejaga kelestarian hutan, memelihara pohon bakau di tepi pantai dan menjaga abrasi pantai, membuat lingkungan tempat tinggal tetap alami. Selain itu pencemaran terjadi di danau akibat banyaknya keramba ikan di danau. Ketika air tercemari pakan ikan yang berlebihkan maka air yang dulu berwarna biru kehijauan kini menjadi keruh dan beraroma tidak sedap.

Masyarakat sebagai pelaku aktivitas harus mempertimbangkan alam ketika akan memulai pekerjaan ataupun ketika sedang melakukan pekerjaan agar kepentingan manusia tidak berbenturan dengan kepentingan alam. Hal ini dilakukan untuk menjaga hubungan selaras dengan alam. Kenyamanan bekerja dengan alam dalam segala situasi dan kondisi serta dalam kondisi yang serba terbatas sebagai bentuk pembelajaran mengenai nilai pendidikan lingkungan tercermin dalam kutipan-kutipan berikut.

(7) Dia memberikan teropong ke Attar. "Kau salah lihat. Itu bukan ikan jinak, iku ikan mati membuntah namanya. Keracunan sir danau karena sisa pakan dan kotoran ikan yang menumpuk," kata Attar. Attar dan Zen bercerita bahwa keracunan ini sudah sering terjadi. Besoknya Hepi melihat semakin banyak ikan-ikan yang mengapung dan danau menjadi seperti lautan bangkai ikan. Dan dalam beberapa hari setelah itu angin danau menerbangkan bau anyir dan busuk ke segala penjuru karena bangkai ikan mulai kembung dan berlendir. Para penjaga keramba dan nelayan yang kewalahan membersihkan berton-ton bangkai ini akhirnya membiarkan ikan-ikan mati ini mengapung di air (Fuadi, 2019: 197).

(8) Selama berhari-hari kampung mereka dialiri bau busuk dari danau. Kakek menyuruh mereka menutup jendela surau untuk mengurangi aroma yang memualkan ini, sementara itu Nenek menaruh tadah berisi bubuk kopi si beberapa sudut surau. Di "sarang elang" pun mereka mengunci semua jendela. Bahkan Mak Tuo Ros harus menutup lapaunya beberapa hari karena tidak ada orang yang berselera makan dan minum di lapau yang terletak tidak jauh dari danau (Fuadi, 2019: 197-198).

(9) Begitu lapau Mak Tuo Ros buka lagi, Hepi mendengar Pak Sinayan "mengamuk" di depan teman debatnya dengan pidato panjang. "Danau Talago ini begitu pemaaf. Telah diracu berkali-kali, tapi tidak marah. Danau hanya batuk-batuk dan memuntahkan racun yang ditelannya beberapa hari. setelah itu dengan baik hati kembali membesarkan ikan-ikan kita, menyediakan makanan dan air buat kita. Tapi sampai berapa lama?" dia berhenti sebentar untuk menyesap kopinya dengan kening berkerut (Fuadi, 2019: 198).

Penggalan novel tersebut menjelaskan ketika danau mengeluarkan bau busuk karena ikan yang mati keracunan, warga masih tetap beraktivitas. Meskipun seluruh pintu surau harus ditutup, masyarakat masih melaksanakan salat lima waktu di surau, untuk mengurangi bau busuk tersebut, Nenek menaburkan bubuk kopi ke semua sudut surau. Hepi yang berada di sarang elang yang terdapat di lantai tiga bangunan surau tersebut juga mengunci semua jendela. Hanya lapau -warung- Mak Tuo Ros yang tutup untuk sementara karena tidak ada warga yang berselera makan di warung. Nilai pedidikan lingkungan yang dapat dipelajari dari penggalan kutipan novel tersebut yakni manusia seharusnya senantiasa menjaga dan memelihara lingkungan dengan baik agar menimbulkan kenyamanan untuk menetap dan bekerja dalam situasi dan kondisi alam yang elok dan terpelihara dengan baik. Sebab siklus kehidupan masih akan terus berlanjut dan tidak menutup kemungkinan ketika kita tidak 
memelihara alam sekitar dengan baik maka bencana seperti keracunan ikan di danau sehingga menimbulkan polusi udara tersebut akan kembali terjadi.

(10) Datuk terkejut saat melihat betapa banyak orang yang sebetulnya peduli dan rusuh melihat keadaan kampung ini, tapi selama ini berdiam diri. Mereka bukannya tidak peduli, melainkan hanya belum berani maju sendiri-sendiri. Mereka menunggu ada orang yang memimpin. Mereka menunggu ada warga yang tewas overdosis dulu, danau berkuah racun dulu, rumah-rumah dibongkar maling dulu. Dia melihat ternyata banyak yang duduk menunggu di kampungnya ini. Datuk tidak menyia-nyiakan kesempatan ini. Di atas podium dia berbicara berapi-api, "Para hadirin yang Bahagia. Kemuduran kampung kita ini akan terus terjadi. Bukan karena banyaknya orang jahat, melainkan karena lebih banyak orang baik yang memilih diam dan tidak peduli dengan kampungnya. Pembiaran berjemaah akan menghasilkan penyesalan berjemaah." Tidak ada yang menepuki pidatonya, tapi Datuk yakin kata-katanya telah menembus hati para pendengarnya saat dia melihat banyak yang mengangguk-angguk atau tertunduk. Datuk membatin, biarlah yang tersinggung, tersinggunglah, dia percaya yang tersadarkan lebih banyak (Fuadi, 2019: 349).

Berdasarkan kutipan novel di atas menjelaskan bahwa nilai pendidikan lingkungan harus selalu disebarkan baik dalam situasi resmi maupun tidak resmi seperti dalam pidao memperingati hari lingkungan hidup, di sekolah,, di kantor, di lembaga-lembaga peduli lingkungan, serta melalui karya seperti sastra untuk megedukasi masyarakat terkait pentingnya menjaga dan merawat lingkungan agar tercipta hubungan harmonis antara manusia dan lingkungan. Agar manusia memiliki sikap arif dan bijaksana dalam menjaga dan memelihara alam sehingga tercipta lingkungan yang seimbang. Apabila manusia arif dan bijaksana dalam menjaga dan merawat alam maka akan tercipta lingkungan yang lestari guna keberlanjutan hidup manusia.

\section{Kesimpulan}

Berdasarkan hasil penelitian dapat disimpulkan bahwa novel Anak Rantau memuat nilai pendidikan lingkungan. Fenomena dominan yang disoroti dalam novel tersebut yakni cara manusia menjalin hubungan harmonis antara manusia dengan alam melalui pelestarian lingkungan dalam hal ini menjaga dan merawat alam dengan sebaik-baiknya. Sehingga manusia dapat bersikap arif dan bijaksana dalam menyikapi seluruh kekayaan alam dengan segala isinya demi keberlangsungan hidup manusia di masa yang akan datang.

\section{Saran}

Saran yang dapat disampaikan berdasarkan hasil penelitian ini antara lain adalah; (1) bagi tenaga pendidik baik guru maupun dosen dapat menjadi penghubung untuk mengajarkan nilai pendidikan lingkungan dalam novel Anak Rantau sebagai bahan ajar studi sastra di sekolah maupun di perguruan tinggi khususnya mata pelajaran Bahasa dan Sastra Indonesia dub bidang studi prosa fiksi yang memuat tema lingkungan serta mata kuliah apresiasi prosa fiksi dan mata kuliah ekokritik. (2) Bagi pemerintah, penelitian ini disarankan dapat menjadi bahan pertimbangan bagi pemerataan pembangunan dan pembangunan berbasis lingkungan di Indonesia serta bagi pembaca dan masyarakat secara umum, penelitian ini diharapkan dapat membantu dalam pemilihan bacaan yang memuat nilai-niali pendidikan lingkungan dan nilai pendidikan karakter berbasis kearifan lingkungan bagi pembangunan sumber daya 
manusia yang lebih baik. (3) Bagi penelitian selanjutnya untuk melakukan pengkajian lebih lanjut mengenai nilai lingkungan menggunakan novel-novel Indonesia bertema kedaerahan (lokal) sebagai produk sastra daerah menggunakan teori ekokritik. Selain pada novel, kajian ekokritik juga dapat dilakukan dengan menggunakan produk sastra lisan daerah seperti cerita rakyat atau dongeng daerah sebagai sumber kajian serta dapat pula dijadikan sebagai pengembangan penelitian pendidikan karakter berbasis kearifan lingkungan di sekolah.

\section{Daftar Pustaka}

Afandi, Iswan dan Juanda. (2020). Nilai Lingkungan dalam Cerpen Apakah Rumah Kita Akan Tenggelam Karya Anas S Malo Melalui Tanggapan Mahasiswa (Kajian Ekokritik). Jurnal Kandai, 16 (2), 295-314.

Andriyani, Noni dan Piliang, Wilda Srihastuty Handayani. 2019. Kritik Sastra Ekologis Terhadap Novel-Novel Terbaru Indonesia. GERAM (Gerakan Aktif Menulis), 7(1), 81-89.

Anjan, N dan Sathoskumar, C. (2017). Ecological Concern in Ruskin Bond's Short Stories. Veda's: Journal of English Laguage and Literature (JOELL), 4(4), 287-290.

Asyfa, Nurul dan Putri, Vera Soraya. (2018). Kajian Ekologi Sastra (Ekokritik) dalam Antologi Puisi Merupa Tanah di Ujung Timur Jawa. Seminar Nasional \#4: Eksplorasi Bahasa, Sastra, dan Budaya Jawa Timuran. PS PBSI FKIP Jember.

Budiharto, R. Agus dan Ramadani, Tjitra. (2018). Penggunaan Sastra Lingkungan untuk Membentuk Karakter Siswa Sekolah Dasar Kelas Rendah Peduli Lingkungan. Jurnal ABDIMAS BSI, 1(2), 180-185.

Darmawati, M.R. (2017). Manusia Kelapa dalam Perspektif Ekokritik. Seminar Nasional Bulan Bahasa 2017. 163-169.

Fenn, Vathana. (2015). Roots of Ecocriticism: An Exploration of The History of Ecocriticism, A Literary Theory of The Post-Modern World. Veda's: Journal of English Language and Literature (JOELL), 2(2), 104-109.

Flinn, Margareth C. (2018). Popular Terroir: Bande Dessinee as Pastoral Ecocriticism? Studied in $20^{\text {th }} \& 21^{\text {st }}$ Century Literature. 43(1), 1-21.

Fuadi, Ahmad. 2019. Anak Rantau. Jakarta: Falcon.

Gifford, Terry. (1999). Pastoral. New York and London: Reutledge.

Glothfelty, C dan Fromm, Harold. (1996). The Ecocriticisim Reader: Landmarks in Literary Ecology. London: University of Georgia Press.

Juanda, Juanda. (2019a). Ekokritik Film Avatar Karya James Cameron Sarana Pendidikan Lingkungan Siswa. Jurnal Pendidikan Bahasa dan Sastra Indonesia, 8(1), 1-9.

Juanda, Juanda. (2019b). Revitalisasi Nilai dalam Dongeng Sebagai Wahana Pembentukan Karakter Anak Usia Dini. Jurnal Pustaka Budaya, 5(2), 11-18.

Larasati, Maria Marietta Bali. 2020. Representasi Kerusakan Alam dan Nilai Kearifan Lokal dalam Cerpen Kanuku Lon Karya Christian Dicky Senda. Jurnal Ilmiah Edukasi \& Sosial, 7(2), 167-176.

Lisnasari, Lilik dan Sukmawan, Sony. (2016). Berhulu Welasasih Pepitu, Bermuara Narasi Arcadia: Kajian Ekokritik Cerita Rakyat Tengger. Jurnal Ilmiah Edukasi \& Sosial, 7(2), 167-176.

Miles, M.B and Huberman, A.M, and Saldana, J. (2014). Qualitative Data Analysis and Method Sourcebook (3ed.). Arizona: SAGE Publication.

Putri, Nina Queena Hadi., Afifah, Nisa Fitriyani., Rahman, Hasrul. (2019). Kearifan Lingkungan Masyarakat Dayak Benuaq dalam Novel Api Awan Asap: Kajian Ekokritik Giiford. Jurnal Satwika, 3 (2), 132-141. 
Sultoni, Ahmad. (2020). Kritik Ekologi dalam Buku Puisi Air Mata Manggar KArya Arif Hidayat: Kajian Ekokritik Sastra. JP-BSI: Jurnal Pendidikan Bahasa dan Sastra Indonesia, 5(1), 6-10.

Syam, Essy dan Aris, Qori Islami. (2020). Perlakuakn Terhadap Alam yang Tercermin dalam Teks Alinta, The Flame, Karya Hyllus Maris dan Sonia Borg: Kajian Ekokritik. Prosiding Seminar Nasional Pakar Ke-3, 1-5

Winda, Novia dan Bahri, Saiful. (2020). Ekologi Alam di Tanah Baduy dalam Novel Baiat Cinta di Tanah Baduy Karya Uten Sutendi. Stilistika: Jurnal Bahasa, Sastra, dan Pengajarannya, 5(2), 256-163. 